\title{
Research on engineering education based on university-enterprise cooperation
}

\author{
Tong Yifei ${ }^{1, a}$, Zhao Ling ${ }^{2, b}$, Wang Huifen ${ }^{3, c}$ \\ ${ }^{1}$ School of Mechanical Engineering, Nanjing University of Science and Technology, Nanjing, \\ People's Republic of China \\ ${ }^{2}$ School of Mechanical Engineering, Nanjing University of Science and Technology, Nanjing, \\ People's Republic of China \\ a tyf51129@aliyun.com, ${ }^{b} 2317046412 @ q q . c o m,{ }^{c}$ nust8351121@126.com
}

Keywords: Engineering education; University-enterprise cooperation ; Course construction; Talent training; Continuous improvement

\begin{abstract}
With the education idea updating and high demand of talents from universities by enterprises, a new idea and mode of engineering education was proposed. In China, with the proposal and advancement of CDIO (Conceive-Design-Implement-Operate)and "Excellence Engineer", engineering education is under more and more attention. In Nanjing University of Science and Technology, the implementation of engineering education is put forward on the schedule, not only for undergraduates, but also for postgraduates. In this paper, the systematical framework of how to improve the training quality with engineering education of Nanjing University of Science and Technology is presented. The university-enterprise course construction is discussed in detail. How enterprises play a good role in engineering education and talent training is pointed out. Finally, the continuous improvement architecture of engineering education quality is proposed.
\end{abstract}

\section{Introduction}

With the education idea updating and high demand of talents from universities by enterprises, a new idea and mode of engineering education was proposed[1]. In China, with the proposal and advancement of CDIO (Conceive-Design-Implement-Operate) [2] and "Excellence Engineer", engineering education [3] is under more and more attention.

Engineering education focuses on instill of engineering idea and training of engineering ability. Traditional talent training and university education pay more attention on theoretical course teaching and less on practical ability to solve actual problems from engineering project. Therefore, there would be a gap between the theory learn and application of knowledge. And it is difficult for students to combine the theoretical knowledge with engineering practice. However, in view of employers, it is hopeful of employees to handle jobs as soon as possible. So it is of great significance and benefits to study how university implements engineering education and train talents with more competitiveness so as to obtain "win-win-win".

Nanjing University of Science and Technology was founded in 1953, and has been resolving to create a brighter future. With the motto of Unity, Dedication, Truth and Innovation, Nanjing University of Science and Technology is dedicated to the well-being of Chinese society and to world development by providing outstanding research and talent training. As for talents training, Nanjing University of Science and Technology aims to offer comprehensive theory and professional skill education for students to obtain great competitiveness and engineering problems solving ability. To achieve these, CDIO, "Excellence Engineer" and other advanced education mode have been tried and gained excellent outcomes. Engineering education, as a new mode, is advancing in Nanjing University of Science and Technology for undergraduate engineering education accreditation and graduate education quality improvement. In this paper, how to implementation the Engineering education will be discussed in detail. 


\section{Engineering education framework of NUST}

In order to better implementation the Engineering education within the scope of NUST, an engineering education framework is presented as shown in Fig.1.

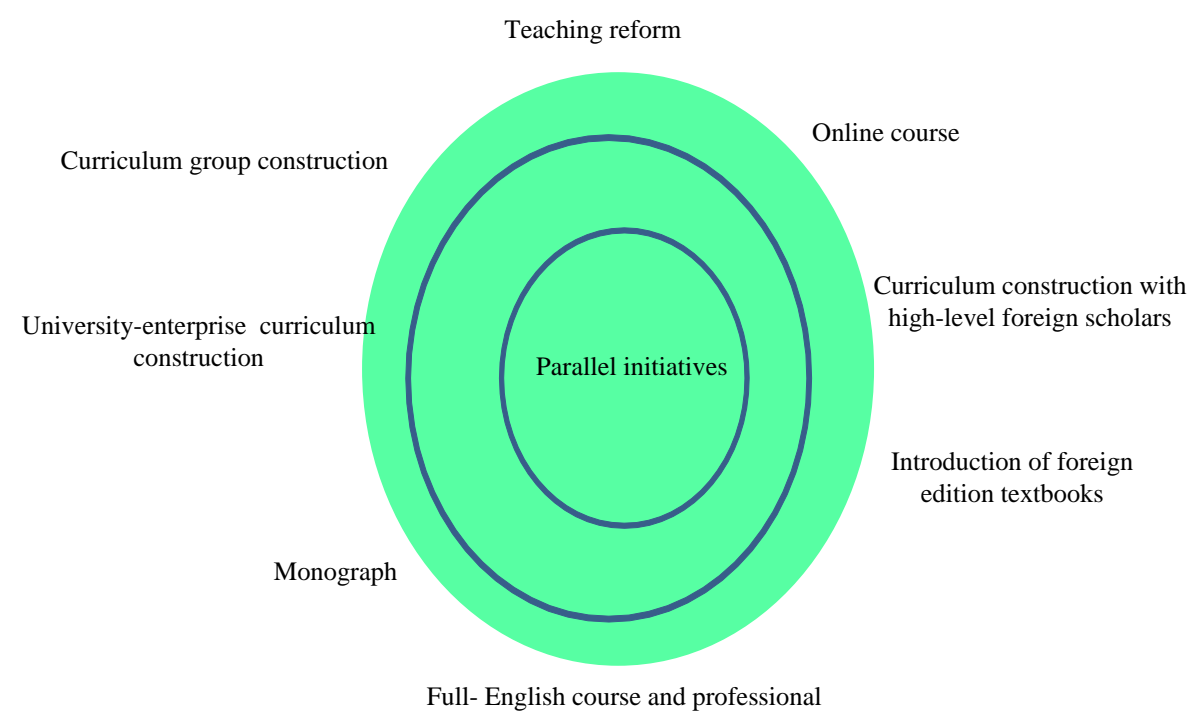

Fig.1 Engineering education framework of NUST

As shown above, the engineering education framework of NUST mainly contains eight parallel initiatives.

1) Teaching reform research. NUST encourages teachers to explore novelty teaching mode and innovative teaching method with changing environments and times.

2) Online course development. Development of online courses, such as video, Micro lesson , MOOC, can favor students to study at any time and any place.

3) Curriculum group construction. Construction of curriculum group is to integrate courses with common intersections under certain focus.

4) University-enterprise curriculum construction. That is, to develop some core courses by efforts of university scholars and enterprise engineers and researches.

5) Curriculum construction with high-level foreign scholars. That is , to develop some courses by efforts of university scholars at home and abroad.

6) Monograph. Compile/ compose some academic books will favor the dissemination of academic thought and guidance of research work.

7) Introduction of foreign edition textbooks. Some classical foreign edition textbooks can favor the students to understand the knowledge, and also it is the destination to carry out original textbooks composition after digestion of foreign edition textbooks.

8) Full- English course and professional. Construction of full English course and professional can favor the globalization of universities and magnifying the influence of universities.

\section{University-enterprise course construction}

The university-enterprise course construction aims to cultivate high-level comprehensive practical personnel for national economy by setting courses with the guidance of practical application , the goal of professional needs, and the core of improvements about comprehensive practice literacy and application of knowledge and ability.

To construct university-enterprise course, the following work will be involved.

(1) Research and construction of curriculum system. That is to determine the status and role of the curriculum, and clear the concepts and ideas so as to ensure the curriculum system in line with corresponding training objectives. 
(2) Research on Teaching Content and Textbook Construction. Through cooperation with relevant industry enterprises, extensively absorb and systematically summary modern professional professional engineering practice in the field of related theory, knowledge, experience and success cases to realize the combinations of theories with practice, according to industry business development needs. Meanwhile, select engineering practice as teaching contents to lay a good foundation for the sustainable development of students, and cooperate with business experts to write three-dimensional teaching resources .

(3) Research of teaching methods. Make full use of modern educational multimedia and network technology based on course contents and student's characteristics.

(4) Teaching Staff: According to course contents and actual needs, recruit and hire experts from related industries and enterprises to co-complete the course construction tasks.

(5) Construction of practical teaching environments. Aware the importance of off-campus practice resource utilization, and meanwhile, according to the principle of complementary, mutual assistance, and mutual benefit, construct the practical teaching environments with enterprises.

\section{The role of enterprises for engineering education}

How to develop the enterprise partner and to make full use of them remains an emphasis for universities to fulfill engineering education. Here, the following suggestions about the above issues are presented according to the theory exploration and the authors' experiences.

1) Seek some famous enterprises from research partners as talent training base to off internships and provide some projects.

2) List some research projects from enterprises for project-based course teaching, comprehensive course design and thesis.

3) Enterprises can provide some materials for teaching, such as production video, engineering cases, technological reports and so on.

4) Invite enterprise experts into class and undertake some teaching tasks or guide students to make projects.

\section{Continuous improvement of engineering education}

In the context of engineering education, it need strive to advance the ideas of improving the quality into sound system and policies and put into scientific methods and practices. This requires:

1) Establish a scientific, nationalization, sound education quality standards, while strengthening quality education awareness.

2) Form a continuous improvement of quality assurance mechanisms, including the internal-external quality management system, continuous improvement of management mechanism and quality culture.

According to the professional certification standards for engineering education, with full consideration to future engineers training objectives, continuous improvement of engineering education is studied from the views of system construction, process monitoring and outcome evaluation. By applying some ideas and methodologies of Industrial Engineering, the framework for continuous improvement of engineering education of Nanjing University of Science and Technology is proposed as in Fig. 2. 


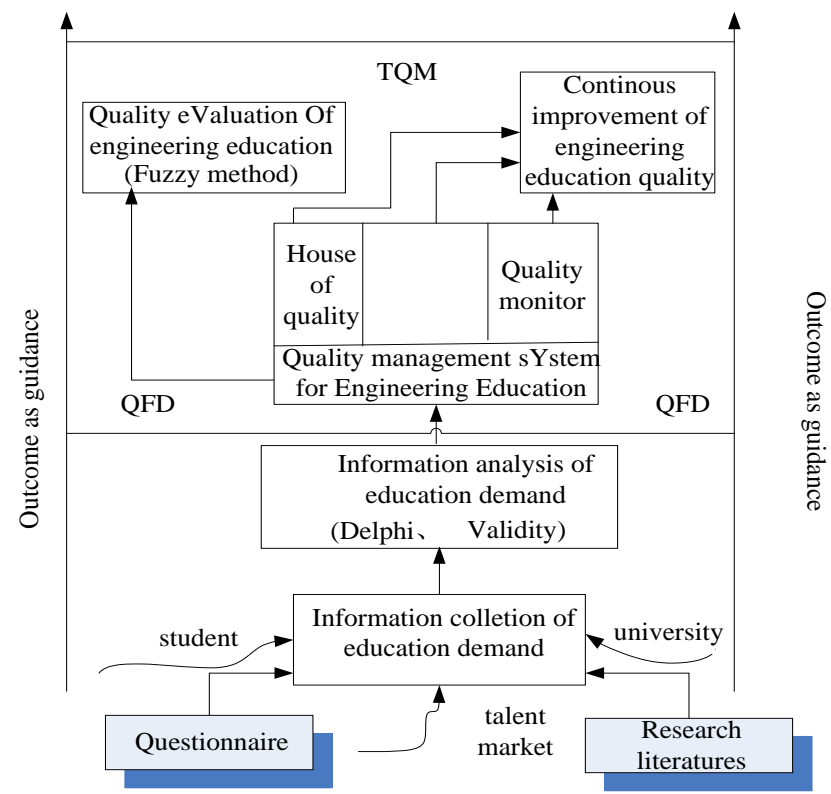

Fig.2 Framework for continuous improvement of engineering education of NUST

1) student-centered and outcomes-oriented educational demand information acquisition and analysis

Based on the survey and comparative law literatures, collect education demand information. Using Delphi to analyze and induct quality requirements element, explore the influence mechanism of educational demands on quality management by inspecting the validity of quality requirements elements based on SPSS software.

2) System construction, monitoring and continuous improvement of engineering education quality

QFD (Quality Function Deployment) [4] and TQM (Total Quality Management) [5] are throughout the entire process of system construction, monitoring and continuous improvement for engineering education quality. Firstly, according to the characteristics of engineering education in colleges and universities to determine the stage of QFD and House of Quality. Then construct engineering education quality management system based on TQM. Combined with NUST's education development status and present quality assurance system, establish a teaching quality control structure (focusing on engineering education practice process monitoring) by utilizing Total Quality Management (TQM) and draw up corresponding systems and operation mechanisms to support continuous improvement of education quality.

3) Fuzzy comprehensive evaluation of engineering education quality

Propose a college engineering education quality evaluation system based on TQM and apply fuzzy mathematical theory to make fuzzy comprehensive evaluation of engineering education quality.

\section{Conclusions}

How to realize engineering education to improve the talent training quality is one of the hot pots and trend for university education. By addressing this problems, it will promote the education reform and satisfy the employers as well. Therefore, the efforts have been concentrated on this issue and some new potential methods for continuous quality improvements for education engineering have been discussed.

However, current research to on engineering education still stays on the level of theory and framework. Therefore, the above work is just a preliminary attempt. Before it can be wildly used in practice, there still exists a great deal of works to be done in future. Although, University-enterprise course construction is discussed in detail, the issues involved remain important and necessary in university education reform. For example, the following works are required, including teaching 
mode reform, teaching method diversification, high-level faculty, textbooks and monograph composition, University-enterprise cooperation, online Teaching Resources and so forth.

\section{Acknowledgments}

This work was supported by Brand professional construction Project of Jiangsu university under grant number PPZY2015B119 and the higher education reform Research Funds of Nanjing University of Science and Technology.

\section{References}

[1] Litzinger T, Lattuca L R, Hadgraft R, et al., Engineering education and the development of expertise, Journal of Engineering Education-Washington. 100(2011)123.

[2] Wang Y, Qi Z, Li Z, et al., Review of CDIO Research in China: from 2005 to 2011, World Transactions on Engineering and Technology Education. 10(2012) 70-76.

[3] Hu H S, Cao J, Training Mode Reform of Application Excellence Engineer in Mechatronics Subject Field for Local University, Applied Mechanics and Materials. 224(2012) 489-492.

[4] Qureshi M I, Bhatti M N, Rasli A M, et al., The Delphi Method for Internationalization of Higher Education in Pakistan: Integrating Theory of Constraints and Quality Function Deployment, Mediterranean Journal of Social Sciences. 20(2014) 2702.

[5] Li J, Study on Total Quality Management System Construction for Higher Education, Advances in Social Science Education and Humanities Research. 30(2015) 477-480. 